\title{
The Imbrication of Patriarchy, Racism, and Transnationalism and the Ensuing Gender Relations in Selected GUMIL Hawaii Short Fiction circa 70s
}

\author{
Ma. Socorro Q. Perez
}

\section{ABSTRACT}

The Gunglo Dagiti Mannurat iti Ilokano ti Hawaii (GUMIL Hawaii), a community-based association of llocano writers in Hawaii, dramatizes in their writings the diasporic condition of Filipino immigrants, especially of the llocanos, in that foreign land. A particular topic these writers depict in their works is the resulting marital and domestic conflict due to arranged marriages between young girls and much older male laborers. The author hopes that by using a gender relations framework that is informed by an awareness of the intersection of patriarchy, transnational logic, and historicity, she can understand the gender issues at play in the stories selected for this analysis. The article will thus argue that gender relations between Fil-American men and women, particularly of the llocanos in Hawaii, are predicated on the imbrication of patriarchy, classed racism, US immigration policies, the flow of transnational capital, and racist US economic demands.

KEYWORDS: GUMIL Hawaii, feminism, transnational gender relations, diasporic writing

Introduction

Patriarchy has traditionally been singled out as the culprit in explaining the uneven relationship between men and women. However, the incursion of globalization and its logic of dispersed trajectory which revved up into 
full momentum in the 60s has resulted in the restructuring of institutional forms, one of which is the reversal of traditional family roles and the resulting gender relations. Grasping cultural and social practices, such as gender relations, neo-colonial relations, and racism, demands their being situated within the global or transnational framework. For example, Hawaii's sugar industry in the early $20^{\text {th }}$ century, which developed and escalated in the 40 s, relied on the transnational movement of people of the Pacific Islands and Asia Pacific-the Philippines, being one source of cheap labor at that time. In turn, such US economic imperatives engendered complex ramifications in terms of neo-colonial and gender interactions. The demand for single, robust plantation labor from the Philippines had resulted in the concentration of unmarried Filipino laborers in Hawaii's plantations. Married recruits often did not declare their true status (Cariaga 2). However, when marriage became acceptable among the sakada or Filipino plantation laborers-many of whom were of retirement age-they flew home to the Philippines to search for a bride. On the other hand, the attraction of seeing paradisal Hawaii, the need to alleviate a difficult life back home, and the desire to become a US citizen, proved to be the main reasons that compelled young Filipino women-majority of whom were half their groom's age-to agree to such marriage proposals. Some marriages of convenience, however, turned out to be a nightmare for many of the brides. The contract and its ensuing gender relationships spawned untold marital strife, bringing about all sorts of social and domestic problems. Thus, given this scenario, the transnational condition the subjects (specifically the Ilocanos in Hawaii) found themselves in was not just a patriarchal question, but one that necessitated the interrogation of both the local and the global, the interrelation/intersection of private and the public spheres in which Asian-American relations were enmeshed.

For 40 years now, Gunglo Dagiti Mannurat iti Ilokano ti Hawaii (GUMIL Hawaii), a community-based association of Ilocano writers in Hawaii, dramatizes in literature the life, experiences, preoccupations, and the diasporic condition of Filipino immigrants, particularly the Ilocano community, in Hawaii. One particular diasporic topic the GUMIL Hawaii writers often render in their fiction and drama concerns the marital and domestic conflicts of arranged marriages between a much older man and a much younger wife. This subject preoccupied many GUMIL Hawaii writers, particularly in the 70s, as it coincided with the trend of numerous Ilocano sakada workers flying home to take wives, most of whom were young women. This phenomenon might be 
attributed to a juncture of events, such as the 1965 Immigration Act or Family Reunification Act and the Balikbayan Program of the Philippines.

The employment of a gender relations framework, crucially informed by the intersection of patriarchy, transnational logic, and the specificity of historical moments, hopes to yield a critical understanding of gender issues and relations that are played out in selected GUMIL Hawaii short stories or "sarita." Thus, this paper argues that the resulting gender relations between Fil-American men and women, in this case the Ilocano men and women in Hawaii, are predicated on the imbrication of patriarchy, classed racism, US immigration policies, the flow of transnational capital, and the racializing systems of US economic imperatives. "It is along these intersecting lines that we must interrogate several historical factors that come into play in these selected "sarita." These factors are, (1) the desire among Filipinos for upward mobility that impelled them to take part in transnational migrations (including both as plantation laborers as well as parties to marriages for convenience); (2) the juncture of historical events that include the 1965 Immigration Act and the Balikbayan Project; (3) the decline of Hawaii's sugar industry; and (4) the subsequent boom in the Hawaiian tourism industry. In doing this, we will be able to grasp the nuances of gender relations, female subordination and classed racism as reflected in the chosen stories."

\section{Gender Relations Framework and its Intersection with Transnational Capital}

Talking about Asian American experience, Yen Le Espiritu posits that the task of "conceptualizing gender relations is not a private matter between Asian American women and men but as a social, historical, and transnational affair that exposes multiple and interrelated forms of power relations" (47). Lisa Lowe adds that "feminist struggles can't be limited to the study or interrogation of patriarchy within the current global restructuring of capitalism" (357). Female subordination and forms of social relations that emerge, such as gender relations, female marginalization, or even feminist, struggles are products of the interminable intersection of transnational expansion, neocolonial practices, racism, patriarchy, and class distinctions. Judith Newton asserts that the issues of gender relations, gender struggle, women, and women's activities and power, are seen as "being within history, seen as having significant or 
causative relation to the political and economic realms traditionally associated with men" (105). Given the present conjuncture, one can understand gender relations, the female experience, and female struggles and activities not as something autonomous or limited to mere patriarchal issues that are seen as private, but as framed within the interconnectedness of public spheres. More crucially, in addressing how these intersecting axes have come to conspire in the constitution and formation of subjects, such as women, one may be able to find a way to make these axes serve as a possible space for female agency. Moreover, the configurations that arise in the intersection of these axes may be recovered to become sites of contradiction and resistance against patriarchal hegemony and the tyranny of transnational determinations. However, addressing the sites of contradiction and possibilities of agency for women is not within the purview of the present work and requires a separate study.

In light of the present study several factors demand that the analysis of the stories be situated within racialized, transnational conditions within which the subject is inevitably constituted: the migration of Filipinos to Hawaii as cheap labor, the movement of new male and female immigrants years after (particularly with the passage of 1965 Immigration Act or Family Unification Act), and the resulting gender relations of Hawaii-based Filipinos (in this case, of Ilocano men and women immigrants). The dynamics and nexus of political economy resonate in multiple ways with female experience and gender dynamics. The study of gender relations, however, has often been elided (Newton 90), subordinated by the study of patriarchy, of anti-colonial and postcolonial concerns which was the dominant framework before. As a result, the specificities of women's plight, struggles, and movements are eclipsed.

The project of foregrounding the contemporary situation of women begins with the task of articulating the encounter of women with the notion of modernity. Modernity is the meeting of

racialized and gendered regimes of the colonial state and the modern-nation state, which extend not only to the formation and reproduction of gender in the family and in other social spaces and institutions such as schooling, religion, law, the workplace, and cultural and popular media, but to ideological and epistemological suppositions of the particular and the universal construction of interiority and exteriority and evaluation of purity and impurity. (Lowe and Lloyd 17) 
One notes the multiplicity and simultaneity of institutions that conspire in the formation and subordination of women, hardly allowing elbow room for negotiation. Such material practices, articulated in and legitimated by these institutions, reinforce and render legitimate and natural through ideological and epistemological suppositions the construction of women as docile subjects. According to Lowe, while modern nation-states and liberal feminism have engendered female empowerment, such progress remains on the level of theory, as the consolidated national identity foregrounded in the era of modernity excludes women, especially from important areas such as politics, law, education, and economics. The political and economic realms are traditionally presumed male, and run in opposition to the realms understood as "feminine," which include the "domestic sphere of the 'home,' the 'spiritual,' cultural antecedents of modernity and labors situated as reproductive" (Lowe and Lloyd 18). The antinomy between the concerns, territory, and space of the male (political, economic, juridical) and those of the female (home, spiritual, culture), precludes women from participating in "male" forms of institutions.

The structures of patriarchal society regulate and discipline women into female subjects primed for the task of the distribution and the production of patriarchal practices. These structures, however, are refunctioned or "reterritorialized" by the imperatives of global capital. This "modern patriarchal state form persists within the mobility of global capital as the primary set of institutions for regulating women's labor and sexuality and for dictating spheres of gendered social practice" (Lowe and Lloyd 19). In the transnational era, the so-called liberal ideologies of development-such as free trade, the free market, progress, democracy, and freedom-reorganize and reconstitute the structures of modern states and the operation of production in order to advance the flow of global capital and the movement of the market (Harvey 2). Such reconstitution of these forms allows for the "commoditization" of women, precisely in "ways permitted by their subordination by national patriarchal states. Patriarchal definitions of gender are continuously reproduced throughout a genealogy of social formation" (Lowe and Lloyd 20), the latter of which is predicated by the flow of capital and globalization. One notes the relentless patriarchal institutions that render the formation of women into patriarchy's docile subjects. Lowe and Lloyd maintain that "there is a perpetual dialectic between 'traditional' patriarchy and its 'modern' rearticulations, whereby the selective redefinition of the 'traditional' woman through which modernity rearticulates patriarchy, serves both to intensify the constraints 
upon ... female subjects" (20). Moreover, Lowe and Lloyd argue that transnational capital makes use of the "structures of patriarchal societies and their modes of gender discipline to maximize the exploitation of 'docile' female ..., simultaneously reproducing patriarchies by moving women from one sphere of gendered social control to another" (21). In other words, one way to ensure the flow of global capitalism and the reconstitution of women is to rely on traditional patriarchal institutions of control, such as the family. Such "cultural regulations" are refunctioned by transnational capitalism to bring about female regulation and discipline within intersecting institutions such as the house, the workplace, politics, and culture.

How does the transnational circuiting of capital affect the politics of culture? This study aims to explore this effect on gender relations, especially on female subordination, as evident in selected GUMIL Hawaii Fiction. The study will demand the articulation of the originary history and context of the Ilocano community in Hawaii. It must be understood that the nexus of classed racism and racialized immigration policies, conflated with oppressive plantation policies and transnational circulation, conspire to bring about the marginalization of immigrant Filipino plantation laborers. Such intersecting axes of domination subsumed the Filipino plantation laborers, led to their exploitation and subordination, and shaped the constitution of female Filipino immigrants and the corresponding gender relations.

The sugar industry in its transnational logic of capital demanded and relied upon the migration of labor to man the plantation fields of Hawaii. The United States used the colonial status of the Philippines as their excuse to transport Filipinos to Hawaii as US nationals, but without the full rights accorded to US citizens (San Juan 446; Cordova 30). The status of Filipinos recruited and commissioned for Hawaii as cheap labor marks the unequal relationship between US and the Filipinos from the start. While these Filipinos were technically US nationals, they were treated as mere contract workers (San Juan 446).

This asymmetrical relationship between hegemonic white plantation owners, known as the Big Five (C.Brewer \& Co. founded in 1826, Theo.H. Davies \& Co., 1845, AmFac Inc., 1849, Castle \& Cooke Inc., 1851, Alexander $\&$ Baldwin, Inc., 1895) and the Filipino plantation laborers was further rein- 
forced by racializing structures. Deemed as unskilled, uneducated, and unassimilable, the Filipinos were classified at the lowest rank in the occupational stratification order. Given that transnational circuiting is driven by profit, it was strongly discouraged to bring along one's family, who were considered non-productive dependents. This resulted in an abnormal sex ratio among Filipino immigrants (Cariaga 3). In "1920, the ratio between Filipino men and women was twenty to one, in 1930, nineteen to one; in 1950, six to one" (Cordova 32). Moreover, the phenomenon of the uneven sex ratio yielded social and domestic problems-wife-stealing and men fighting over women are just two examples.

The Filipino laborers were constituted as a specific resource from the beginning, a "mode of capitalist discipline for forming workers who will fit into the current needs of transnational capital" (Lowe and Lloyd 22). The uneven sex ratio in Hawaii's plantation life, as a consequence of the intersecting axes of patriarchy, racialized immigration policies, racist structures, and the flow of global capital, effected, in turn, the feminization and racialization of male labor, as the plantation laborers were constrained to do what is traditionally classified as female domestic work in the barracks, on top of 10 or 12 hours of masculine, back-breaking labor in the plantations. The racialization of Filipino labor, along with immigration and plantation policies (which strictly required a single status) produced far-reaching effects, the most crucial of which was that workers were compelled to remain unmarried during the prime and for most of their lives.

The 1965 Immigration Act, which lifted the 50-a-year quota of immigrants entering the US, ushered in the opportunity for Filipino plantation laborers to think of the previously unthinkable option-marriage. However, many of these marriages of convenience became a source of marital and domestic conflict between Filipino husbands and wives. The paper will interrogate the broader historical contexts in which the selected GUMIL Hawaii fiction take place in order to more critically understand female experience and struggle, and the corresponding gender relations between husbands and wives as seen in the stories. The study will look into the dynamics between men and women, female experiences and subordination, and gender relations, as constituted by intersecting historical, economic, social, and political forces. 


\section{Contextualizing and Historicizing the Ilocano Immigrant Community in Hawaii}

In 1906, when the first batch of Filipinos arrived in Hawaii as plantation laborers, the island was an expanding capitalist economy and a huge producer of sugar. This economic leadership necessitated a reliance on the migration and transport of cheap labor: "the migration of Filipino workers to Hawaii, from 1906 to 1946, took place within the context of an ever-increasing capitalist penetration of the islands and Hawaii's concomitant absorption into the world capitalist economy" (Sharma [quoting Kent] 579). Before the advent of the practice of sourcing Filipino laborers to man the sugar plantation fields, labor and man-power were largely provided by the Chinese, Japanese, Koreans, and some other minority white groups. However, the increasing expansion of the sugar market and the falling out between the Japanese laborers and their white plantation owners, seen in the Gentleman's Agreement that cut off Japanese labor supply (Porteus and Babcock 58; San Buenaventura 75; Sharma 581), compelled the Big Five white plantation owners to look for labor elsewhere. Since the primary concern is getting a constant and steady flow of cheap labor, the Big Five "regarded the increasing aggressiveness of 'Asiatics' as a serious threat to the prosperity of the sugar industry" (Sharma 581). The fact that the US annexed the Philippines at around the same time as Hawaii in 1898, which turned the former into a colony, gave the white plantation owners the license to transport bodies to Hawaii. The Philippines' proximity to Hawaii was also a huge factor in the US commissioning Filipino plantation laborers, instead of workers from, say, Puerto Rico, which was also a colony of the US, but which is at the other side of the world (Cariaga 5; Cordova 28).

The Hawaii Sugar Plantation Association (HSPA), a recruitment agency, came to the Philippines to hire new labor. In systematic fashion, the agency put up two recruitment centers-one in the Visayas and another in Ilocos Province. The ideal applicant for the recruitment agency was one who was used to manual labor and was not too citified in his ways and sensibilities. An official of HSPA claims, "we want unskilled laborers for the plantation. They wouldn't be too unhappy to do manual work... ten hours a day. So, give us rural people..." (Alcantara 28).

The year 1906 marked the beginning of four waves of Filipino labor migration to Hawaii. By the mid-1930s, there were roughly 54,600 Filipinos in 
Hawaii (Cariaga 1; San Juan 447). By 1945, an estimated 129,000 Filipinos arrived in Hawaii (Teodoro 12). Most of the workers recruited from the Philippines came from Ilocos, the Northern part of the Philippines (Cariaga 5). Throughout the growth and expansion of Hawaii's sugar industry, Philippines steadily became one of the greatest exporters of cheap labor. The circulation of US capital and its imperial-economic imperatives fueled the migration as well as the production of complex private, public, and transnational practices and relationships.

As the advancement of the sugar industry and of capital remained of primary importance, all decisions and transactions were framed after this transnational logic. First, the ideal laborer must be physically strong and must be accustomed to manual labor. He must not be too citified and must be minimally educated. Second, there was a preference for unmarried men because bringing one's family would be too costly for the plantation owners. Plantation policies clearly discouraged it: "first, the cost of living for a family on plantation wages made normal family life almost prohibitive. Second, plantation managers frowned on having to provide special housing, schooling and medical aid to non-productive dependents" (Alcantara 31). Under strict recruitment procedures, only those who qualified were naturally taken. Considered as uneducated and unskilled, the Filipino plantation laborers were classified at the lowest rank of the occupational ladder: "Haoles (Whites) held management positions regardless of education or experience. Spanish and Portuguese were 'lunas' or plantation overseers. The Japanese were given technical and mechanical jobs. To the Filipinos went the lowest jobs... and held down as unskilled laborers for most of their lives" (Cordova 31; Teodoro 13).

Notable is the overt racism in the socio-economic and occupational stratification order in the plantations: "Filipino and other immigrant laborers had to contend with racist attitudes of the growers who firmly believed in the superiority of the Haole or white race over immigrants and Hawaiians" (Teodoro 10). Moreover, as profits remained paramount for the capitalists, they were completely unconcerned about the effects of settling into an unfamiliar environment and the ensuing transplantation of Asian labor to a mechanized and industrialized set-up, which was totally different from the set-up and pace of rural farming back home. Labor, especially that of Asians, was regarded as mere economic commodity that could be disposed of easily. One official 
of HSPA remarked: "there is little difference between the importation of jute bags from India and the laborers" (Teodoro 10).

Practically treated as indentured servants, the Filipino plantation laborer worked under oppressive conditions, getting 70 cents for a grueling 10 hours per day. The absence of labor unions in the early years of the sugar industry made the workers vulnerable to exploitative management practices. But despite such oppressive conditions, many Asians responded to the call to work in the sugar plantation fields, leaving behind wives and children. For most of them, the primary goal was to "work hard, save money and return as quickly as possible to their families in the homeland" (Cordova 32). For the vast majority, working in Hawaii was viewed as a "temporary sojourn" (Okamura 49).

\section{Effects of Racist Plantation Labor Practices and Transnational Imperatives on Gender Relations Seen in Selected GUMIL Hawaii Short Fiction}

The stipulated requirement of single, hardworking, docile labor applicants possessing little education proved ideal for the Big Five since they reckoned such qualities would give them little problems. Since labor unions were unheard of in the early years of the plantation era (Alegado 30), the sugar industry was practically run under oppressive conditions. Wives and women were left behind for there were no provisions for the cultivation of family life. As a consequence, women were denied a "normative family" life and were to fend for themselves and their children (Espiritu 47). Many plantation laborers never came back for their families. Two reasons prevented them from going back: first, they believed that it would be unthinkable to go back as a failure, as folks back home had great expectations and high regard for those who worked overseas. Rather than risk derision, plantation workers who failed (that is, not being able to save enough to buy a bit of property), would opt to remain in Hawaii, and/or live alone, or live a vagabond life (Cariaga 6). Many of the Filipino laborers had already left behind their old lives. (Merina 145). A less common reason is marriage to local women or taking in of common law wives, which caused them to forget their families in the Philippines. Thus, a common scene in Hawaii's plantations was a concentration of single men, either young or old, living bachelor lives (Cariaga 2). The rare arrival of women in the plantations could sometimes cause men to quarrel over the 
attention of the newcomer. While the attention the woman got could be flattering for her, this would often lead to domestic quarrels between the girl and her husband or between her husband against other men. There were also numerous instances when women would run off with another man: this was called "kuboy-kuboy."

The 1965 US Immigration Act opened new opportunities for the sakada workers, who (being of retirement age) were called "Oldtimers." The oldtimers, "those Ilokanos who first arrived in Hawaii from 1906 to the 1930's" (Foronda $\mathrm{xvi}$ ), started thinking of settling down. Many retired single plantation workers contracted late marriages. In light of this, the paper hopes to discuss the following issues: what compelled women from small towns in the Philippines, particularly in the Ilocos province, to enter an arranged marriage with men old enough to be their fathers or even their grandfathers? What kind of relationship transpired between those with disparate ages? What were the causes of domestic conflicts and marriage casualties? Finally, how do intersecting variables of transnationalism, US economic imperatives, migrations and classed racism produce ensuing gender relations?

Furthermore, the Balikbayan Program (Homecoming) of the Philippine Department of Tourism aimed to boost tourism in the Philippines by encouraging Filipino US immigrants to visit their home country. [The sakada workers or the Oldtimers] took this opportunity to visit their country and get wives. The stories tell of a great number of Oldtimers who availed of this program and went home after years of absence, many of whom were able to marry young wives. However, the disparity in their ages caused conflicts and marital frictions. At the onset, the Filipino-girl-brides were ambivalent towards the prospect of entering into a loveless marriage, and even more so, towards marrying older men whom they had just met. The following consequences appear repeatedly in the selected stories: wives getting disillusioned, households disintegrate, and traditional family roles are reconstituted.

The short stories for this study are lifted from different GUMIL Hawaii anthologies: "One Can Learn the Ropes of Love," a novelette ("Masursuro ti Agayat," 1977, Bullalayaw, by Pacita Saludes); "When I Come Back"("Inton Agsubliak," 1972, Beggang, by Pacita Saludes). From Bin-I Ti Biag (2005), of Francisco Ponce, are "The Life of Segundina de Dios"("Maysa a Linabag ti Biag ni Segundina de Dios," 2004); "Divorce Her Cousin!”(“Ay Ket Diborsiam, a Insan," 1977 by Fran- 